\section{Revista Brasileira de Administração Científica}

Brazilian Journal of Scientific Administration

Set a Dez $2018-$ v.9 - n.3

\title{
Dignidade humana no contexto organizacional e suas diferentes concepções
}

O presente artigo tem como objetivo principal compreender o significado de dignidade humana no contexto organizacional e suas diferentes concepções. Tratase de uma revisão da literatura, onde se investigou, inicialmente, o significado de dignidade humana, resgatando suas raízes históricas e filosóficas. Depois, buscouse compreender a maneira como a dignidade está sendo estudada no ambiente organizacional, sobretudo na área de gestão humanizada de pessoas. Os resultados apontam que a dignidade humana possui diversos sentidos, os quais se modificam ao longo do tempo e do espaço. Já, a dignidade organizacional é estudada levando em consideração tanto o ambiente interno quanto o externo à organização. O ambiente interno é tratado na perspectiva de dignidade nas organizações e o ambiente externo sob a perspectiva de dignidade das organizações. Propõe-se, então, uma complementariedade entre estas duas concepções- dignidade nas e das organizações- a fim de obter uma visão mais acurada acerca da dignidade no contexto organizacional. Um dos limites do estudo consiste em não ter investigado empiricamente o que os estudiosos da área pensam acerca da complementariedade apontada, o que poderá ser realizado em outro estudo, constituindo-se numa agenda de pesquisa. Quanto à inovação, aponta-se a possibilidade de repensar a gestão de pessoas, na direção de resgatar a dignidade da pessoa humana no ambiente do trabalho.

Palavras-chave: Dignidade Humana; Significados; Organizações.

\section{Human dignity in the organizational context and its different conceptions}

\begin{abstract}
This article aims to understand the meaning of human dignity in the organizational context and its different conceptions. It is a review of the literature, where the meaning of human dignity was initially investigated, rescuing its historical and philosophical roots. Afterwards, we sought to understand how dignity is being studied in the organizational environment, especially in the area of humanized management of people. The results point out that human dignity has several meanings, which change over time and space. Already, organizational dignity is studied considering both the internal and external environment of the organization. The internal environment is treated in the perspective of dignity in organizations and the external environment from the perspective of the dignity of organizations. It is proposed, therefore, a complementarity between these two conceptions - dignity in and of organizations - in order to obtain a more accurate view of the dignity in the organizational context. One of the limits of the study is that it has not investigated empirically what scholars in the area think about the complementarity pointed out, which can be done in another study, constituting a research agenda. As for innovation, it is possible to rethink the management of people, in the direction of recovering the dignity of the human person in the work environment.
\end{abstract}

Keywords: Human Dignity; Meanings; Organizations.

Topic: Recursos Humanos

Reviewed anonymously in the process of blind peer.
Received: 15/09/2018

Approved: 12/12/2018

Francilene Araújo de Morais

Universidade Presbiteriana Mackenzie, Brasil

http://lattes.cnpq.br/1546276244212200

http://orcid.org/0000-0002-4974-3249

francilene.morais7@gmail.com

Referencing this:

MORAIS, F. A.. Dignidade humana no contexto organizacional e suas diferentes concepções. Revista Brasileira de Administração Científica, v.9, n.3, p.1-12, 2018. DOI: http://doi.org/10.6008/CBPC2179$684 X .2018 .003 .0001$

DOI: 10.6008/CBPC2179-684X.2018.003.0001 


\section{INTRODUÇÃO}

Ao longo da História da humanidade, o significado de dignidade vem diversificando-se e despertando a atenção de pesquisadores de várias áreas do conhecimento (humanas, saúde, exatas, artes, dentre outras, com diferentes perspectivas teóricas, metodológicas e epistemológicas (ARAUJO, 2013).

Desde a antiguidade até os dias atuais, estudiosos já se interessavam em conceituar a expressão 'dignidade humana' (SARLET, 2010). Atualmente, se verifica na literatura que são usados diferentes conceitos ou concepções de dignidade humana nos estudos organizacionais, levando-se em consideração dois eixos principais: o da dignidade nas organizações e o da dignidade das organizações.

No primeiro eixo, busca-se compreender as relações de dignidade no ambiente interno da organização, enquanto no segundo eixo, os estudos de dignidade das organizações consideram o papel avaliativo dos stakeholders externos. Nessa acepção, a pesquisa teve como objetivo compreender o significado de dignidade humana no âmbito organizacional e suas diferentes concepções, conforme consta no resumo.

\section{METODOLOGIA}

Este artigo apresenta uma revisão bibliográfica sobre as concepções de dignidade no contexto organizacional, o qual se baseou nos sentidos de dignidade, que são atribuídos predominantemente ao ambiente interno e externo à organização, denominados, respectivamente de 'dignidade nas organizações' e 'dignidade das organizações'. Em seguida, de maneira reflexiva, analisou-se a possibilidade de uma complementariedade entre ambas concepções a fim de obter uma visão mais acurada sobre o assunto.

Para a contextualização e análise do problema, realizou-se um levantamento bibliográfico através de fontes científicas, procedentes de livros e artigos publicados em periódicos científicos nacionais e internacionais indexados nas bases de dados: ANPAD, SCIELO, SPELL, EBSCO, JSTOR E PROQUEST.

A pesquisa foi realizada no período de 2015 a de 2017 e os estudos foram selecionados a partir dos descritores 'dignidade humana', 'dignidade do trabalhador', 'dignidade organizacional'.

Utilizaram-se como critérios de inclusão resumos e artigos na íntegra publicados em português e inglês, durante o período de 1986 a 2017. Como critério de exclusão definiu-se as referências bibliográficas que não respondiam à questão norteadora. Ao final da investigação científica, a análise foi composta de 57 artigos. No que se refere aos aspectos éticos da pesquisa, o estudo levou em consideração, de maneira fidedigna, tanto as citações das autorias quanto das fontes bibliográficas.

Após o levantamento bibliográfico, foi realizada uma leitura exploratória com o objetivo principal de verificar a relevância das pesquisas científicas consultadas. Em seguida, fez-se uma leitura seletiva das informações, de modo a responder aos objetivos da pesquisa. Posteriormente, realizou-se a leitura analítica, com o intuito de sistematizar as informações obtidas nas fontes de pesquisa para a compreensão das informações sobre dignidade no contexto organizacional. Por fim, procedeu-se a leitura reflexiva e interpretativa dos textos, com a finalidade de compreender os significados dos resultados obtidos, bem como 
relacionar as ideias expressas nas obras consultadas com o problema pesquisado. Efetuando, também, a síntese integradora do material coletado e analisado, que será apresentada em três categorias de análise: Concepções de Dignidade Humana; Concepções de Dignidade Humana e suas raízes e Dignidade nas Organizações e Dignidade das Organizações.

\section{DISCUSSÃO TEÓRICA}

\section{Concepções de Dignidade Humana}

Uma maneira pela qual se pode começar a discussão da dignidade humana consiste em abordá-la sob as seguintes perspectivas: adquirida e/ou inata. Enquanto dignidade adquirida, pode ser concebida como sendo de natureza sociopolítica ou de mérito. E a dignidade associada ao status moral. Ambas são adquiridas no contexto social. Já a concepção de dignidade como valor intrínseco tem um sentido eminentemente inato, no que diz respeito à natureza humana. $\mathrm{E}$ a concepção de dignidade como integridade abrange tanto os aspectos inatos quanto adquiridos (TADD et al., 2010; NORDENFELT, 2003; NORDENFELT, 2004).

Apesar da dignidade sociopolítica e a dignidade como status moral serem adquiridas no contexto social, estas duas concepções diferenciam-se na maneira como o indivíduo as adquire. A dignidade do mérito, ou sociopolítica, é adquirida, mediante o papel social, status pessoal ou posição política e social que a pessoa ocupa na sociedade, ou seja, quanto mais elevada a titularidade das funções públicas, o cargo ocupado (presidente, bispo, prefeito, entre outros) e o reconhecimento da sociedade acerca desse status pessoal, maior será o grau de dignidade que lhe será atribuído. Por sua vez, a dignidade como status moral é adquirida mediante as escolhas morais feitas pelos indivíduos e/ou grupos nas relações interpessoais e sociais. (TADD et al., 2010; NORDENFELT, 2003; NORDENFELT, 2004).

De maneira oposta, a dignidade enquanto valor intrínseco do ser humano não é adquirida socialmente. Em vez disso, é herdada por todos os indivíduos ao nascerem, independentemente de suas características sociais, mentais ou físicas, fazendo parte de sua natureza humana. Deriva da ideia judaicocristã, de que fomos criados à imagem e semelhança de Deus ou por sermos seres racionais. O ser humano é um ser capaz de fazer escolhas como é defendido, por exemplo, pela filosofia estoica e kantiana. A dignidade, nesse sentido, constitui-se num valor inalienável do ser humano, que ninguém pode comprar, tirar e nem tão pouco destruir ou contestar (TADD et al., 2010; NORDENFELT, 2003; NORDENFELT, 2004; KOEHN et al., 2008).

Tal concepção está acentuadamente presente nas culturas de dignidade que, dentre outros aspectos, possuem as seguintes características: priorizam a preservação do 'eu', conferindo-lhe soberania em relação à opinião de outras pessoas e instituições; buscam balancear as ideias de igualdade, no que diz respeito ao fato de que, ao nascer, os seres humanos passam a ter direitos iguais, juntamente com as concepções de liberdade, no que se refere ao valor da pessoa humana, independente dos julgamentos de terceiros; preservação das possibilidades de escolha e de autonomia nas interações interpessoais, em detrimento de 
tentativas de controlar a liberdade das pessoas (KOEHN et al., 2008; COHEN et al. 2011; KIM et al., 2010; KIM et al., 2010).

A concepção de dignidade como integridade ou identidade da pessoa humana corresponde ao sentido de dignidade social que, entre outros aspectos, abrange dois tipos de dignidade: a do self e a relacional. A dignidade do self corresponde ao auto respeito e autovalor, podendo ser identificada nas relações, mediante características de confiança e de integridade. A dignidade relacional é construída nas interações entre indivíduos, grupos e sociedade, refere-se à presença de respeito e de valorização em direção ao outro, podendo ser expressa mediante comportamentos individuais e coletivos. Ambos os tipos de dignidade são suscetíveis de violação, podendo causar traumas na vida das pessoas, à medida que sua identidade é afetada e o seu senso de responsabilidade e de autonomia. A violação da dignidade é passível de ocorrer em relações assimétricas, ou seja, quando o poder, a autoridade de uma das pessoas é maior que a da outra (JACOBSON, 2007, 2009).

Entre as ações que podem violar a dignidade, inibindo a autoestima e a autoconfiança, tornando as pessoas que tiveram sua dignidade violada, mencionam-se os seguintes exemplos: interferências físicas (machucões físicos), danos emocionais; insultos psicológicos, como a humilhação; restrição da autonomia ou exclusão das pessoas da interação social (TADD et al., 2010); NORDENFELT, 2003; NORDENFELT, 2004; MATTSON et al., 2011; WEEK, 2013; OECD, 2013), intromissão na vida privada, mediante a divulgação de acontecimentos que podem ferir a dignidade individual do ser humano como, por exemplo, a publicação de fotos e/ou imagens de pessoas sendo abusadas sexualmente e também que foram feridas em tragédias, como a do "World Trade Center", em Nova York (HORTON, 2004).

A promoção da dignidade do self e a relacional, aqui compreendida como dignidade da integridade ou identidade, ocorre quando um dos indivíduos se encontra autoconfiante e em posição de confiança em relação ao outro. Ou seja, percebe-se como uma pessoa que confia no seu potencial é otimista, perseverante e acredita que coisas boas irão acontecer em sua vida. O outro, por sua vez, encontra-se em uma posição de compaixão, mente "aberta", honesto e tem boas intenções. Sendo assim, o encontro de pessoas com estas características é mais propenso a resultar em promoção de dignidade, tendo em vista que o relacionamento entre elas é de solidariedade, reciprocidade, empatia e confiança. Além disso, contextos sociais que levem em consideração a provisão de renda, a moradia adequada, o acesso à educação e à saúde e o investimento social em bens públicos têm uma maior probabilidade para a promoção da dignidade (JACOBSON, 2009).

Para melhor visualização das diferentes concepções de dignidade humana, elaborou-se o Quadro 01. Onde, evidencia-se que as diversas concepções de dignidade humana, considerando seus aspectos principais, podem ser incluídas em três grupos: dignidade adquirida, dignidade inata e dignidade adquirida e inata. $\mathrm{O}$ primeiro grupo abrange a dignidade sociopolítica ou do mérito e a de status moral. O segundo grupo corresponde a dignidade do valor intrínseco e, por fim, o terceiro grupo à dignidade da integridade. 
Quadro 01: Diferentes Concepções de Dignidade Humana.

\begin{tabular}{|c|c|c|}
\hline \multicolumn{3}{|c|}{ Concepções de Dignidade Humana (TADD et a., 2010; NORDENFELT, 2003, 2004) } \\
\hline Adquirida & Inata & Adquirida e Inata \\
\hline $\begin{array}{l}\text { Sociopolítica ou de Mérito } \\
\text { (papel social, status } \\
\text { pessoal) e Dignidade } \\
\text { associada ao status moral } \\
\text { (escolha moral) }\end{array}$ & $\begin{array}{l}\text { Valor intrínseco e inalienável, que diz } \\
\text { respeito a natureza humana/ Deriva } \\
\text { da ideia judaico-cristã de que fomos } \\
\text { criados a imagem e semelhança de } \\
\text { Deus ou por sermos seres racionais }\end{array}$ & $\begin{array}{l}\text { Dignidade como integridade ou identidade da pessoa } \\
\text { humana corresponde ao sentido de dignidade social } \\
\text { que, entre outros aspectos, abrange dois tipos de } \\
\text { dignidade: a do self (auto respeito e autovalor) e a } \\
\text { relacional. São suscetíveis de serem violadas e/ou } \\
\text { promovidas (JACOBSON, 2007, 2009). }\end{array}$ \\
\hline
\end{tabular}

\section{Concepções de Dignidade Humana e suas Raízes}

As raízes de cada uma das concepções de dignidade humana (sociopolítica, status moral, valor intrínseco e integridade) encontram-se em algum período da História, seja na Antiguidade e/ou na Idade Média e/ou no Renascimento e/ou na Idade Moderna. Num mesmo período histórico, a depender do espaço, existiu e existe mais de uma concepção de dignidade humana, sem necessariamente caracterizar-se por uma substituição ou até mesmo de evolução dessa ao longo do tempo (SARLET, 2010; BARROSO, 2012; BARRETO, 2006).

Na Antiguidade, tanto na Grécia quanto em Roma, observaram-se dois sentidos de dignidade: sociopolítica, ou do mérito, e valor intrínseco. No pensamento clássico grego, uma das abordagens de dignidade relacionava-se a atributos externos ao indivíduo, sendo mais digna a pessoa que ocupasse posições de destaque na sociedade (dignidade sociopolítica). Mulheres e escravos viviam, nesta época, à margem da sociedade e a dignidade era concebida como sendo uma virtude ou mérito adquirido, mediante as relações sociais, estabelecidas pela nobreza. Já no pensamento estoico da Grécia, o homem era colocado acima das demais criaturas, tendo a dignidade como uma qualidade que, por ser inerente ao ser humano, o diferenciava das demais criaturas (SARLET, 2010).

Em Roma, assim como na Grécia, a dignidade da pessoa humana estava relacionada à posição social ocupada pelo indivíduo e ao seu grau de reconhecimento pelos demais membros da sociedade. Por outro lado, com uma visão baseada na filosofia estoica, divulgavam-se os pensamentos de Cícero, que considerava que todo ser humano tinha algum grau de dignidade preservado em sua natureza humana, independente da hierarquia social ou do status pessoal, embora também reconhecesse a existência da dignidade enquanto status social (BARRETO, 2006; SARLET, 2010; GOSDAL, 2007).

As concepções de dignidade sociopolítica e de valor intrínseco adentraram na Idade Média, por influência da Igreja Católica. A dignidade sociopolítica permaneceu sendo conquistada socialmente por meio de status, requerendo do indivíduo sua associação a grupos considerados superiores, como era o caso dos nobres, dos cavaleiros e do clero. A dignidade enquanto valor intrínseco foi defendida por São Tomás de Aquino, que usou o termo 'dignitas humana' para simbolizar a igualdade dos homens perante Deus. Nessa perspectiva, a dignidade era algo absoluto, pertencente à essência. Na Idade Média, o entendimento e a explicação do cosmos ocorriam através de uma visão na qual havia um Deus único que considerava os homens como filhos criados à sua imagem e semelhança (GOSDAL, 2007).

A concepção de que a dignidade humana estava atrelada ao cargo ou função social que o indivíduo exercia na sociedade, bem como à preponderância de determinadas instituições, merecedoras de distinções, 
persistiu no período histórico do Renascimento, derivando-se, deste sentido de dignidade, a honra e a deferência por parte da sociedade como um todo, cujo desrespeito poderia ser sancionado com medidas civis e penais (BARROSO, 2012).

O primeiro escrito específico sobre dignidade, o 'Oratio de hominis dignitate', de Giovanni Pico Della Mirandola, data do período do Renascimento e representou um marco nas concepções de dignidade humana. Nessa obra, a dignidade é associada à liberdade que, por sua vez, é concedida ao homem pelo criador, dando-Ihe a possibilidade de construir, de forma livre e independente, sua própria existência e seu próprio destino, além de torná-lo responsável pelas escolhas realizadas (SARLET, 2010; GOSDAL, 2007).

Nos séculos XVII e XVIII, a concepção de dignidade enquanto valor intrínseco é defendido, tendo em vista a característica humana de razão, não porque seja uma dádiva divina, como era pensamento corrente na Idade Média, mas como possibilidade autônoma de pensar e agir. Recebeu influências do pensamento iluminista de Samuel Pufendorf e do filósofo Immanuel Kant. Para Barreto (2006), dignidade referia-se à liberdade do ser humano para optar, de acordo com sua razão, e agir conforme o seu entendimento e opção.

Para o filósofo Kant (2005), o homem é dotado de dignidade não por ter sido criado a imagem e semelhança de Deus (cristianismo), mas devido à capacidade racional de definir normas e usá-las conscientemente para guiar suas próprias ações, de maneira livre e autônoma. A razão dá ao ser humano uma condição privilegiada que o diferencia dos outros seres vivos. Para ele, a dignidade é o que não tem preço, e a vontade de ser livre está submetida às leis morais. A faculdade de pensar e a autonomia para agir tornam o homem não um meio, mas um fim em si mesmo (SARLET, 2010; BARRETO, 2006; BARROSO, 2012).

A ética Kantiana, segundo Koehn et al. (2008), baseia-se na razão e na lei moral, que demanda que o ser humano deve agir de uma forma coerente e consistente. Logo, não cumprir ou não estar de acordo com as leis morais pode levar os seres humanos a desenvolverem sentimento de culpa, considerados como sendo um alerta contrário à dignidade intrínseca. As ideias de Kant influenciaram os textos jurídicos, inclusive a Declaração Universal dos Direitos Humanos, de 1948 (SARLET, 2010).

As quatro concepções de dignidade humana permanecem na atualidade, estando presentes no século XXI, o que pode ser confirmado, mediante os estudos de Tadd et al. (2010) e Nordenfelt $(2003,2004)$, nos quais, a partir de uma revisão da literatura de trabalhos sobre dignidade com idosos, detectaram os significados de dignidade sociopolítica ou do mérito; valor intrínseco, status moral e identidade ou integridade. A atual concepção de dignidade sociopolítica ou do mérito continua tendo o seu sentido relacionado ao cargo, à posição social e política ocupada pelo indivíduo na sociedade (FERREIRA, 1986; HOUAISS, 2001), apesar das especificidades do contexto histórico, político e social ora vigentes.

Assim como no ocidente, evidencia-se também no oriente a concepção de dignidade humana no sentido sociopolítico. Na cultura chinesa, o respeito à vida está atrelado à posição do homem na sociedade, ou seja, relaciona-se ao papel social exercido pelo indivíduo na sociedade e respectivo status social. Além disso, eles compreendem que a humanidade é dividida entre superiores e inferiores; pessoas nobres e pessoas comuns. Trata-se de uma sociedade hierárquica, na qual algumas pessoas têm mais face do que outras, mesmo que todos tenham alguma face, enquanto estão atingindo as expectativas de suas posições. 
A título de exemplo, cita-se o fato de que a posse de um emprego prestigiado confere à pessoa que o consegue, honra social, assegurando-Ihe sua dignidade. Dessa forma, a riqueza e a honra trazem respeito para as pessoas dentro do sistema social chinês, e a educação e o autodesenvolvimento são caminhos para o sucesso (KOEHN et al., 2008).

Ainda no sistema Chinês, a dignidade é arduamente alcançada pelo indivíduo num contexto de ascensão social, podendo esse indivíduo perder a dignidade. Isto é, aqueles que falham em satisfazer as expectativas da sociedade perderão a dignidade. A dignidade tem um componente material, assim, roupas de "marca", carros caros, refeições em restaurantes caros, por exemplo, são sinais de prosperidade e de poder. Não ter essas coisas origina a perda da face, tendo em vista que são essas coisas que demonstram que o ser humano é digno (KOEHN et al., 2008). A perda da face pode gerar humilhação, à medida que a pessoa aprende uma lição dolorosa sobre seu verdadeiro lugar na hierarquia social (KIM et al., 2010).

A concepção de dignidade humana atrelada ao status moral enfatiza a importância da autonomia moral no que se refere à possibilidade de o ser humano viver de acordo com os próprios princípios morais, em consonância com os da sociedade, tendo em vista que, ao agir com crueldade ou covardia, poderá perder tanto o auto respeito quanto o respeito dos outros (TADD et al., 2010).

Em relação à dignidade como valor intrínseco, essa concepção na atualidade tem sido enfaticamente contemplada nas políticas nacionais e internacionais como, por exemplo, na Declaração Universal dos Direitos Humanos (MATTSON et al., 2011) e constituições nacionais, assim como tem influenciado as discussões e orientações no direito (SARLET, 2010).

A dignidade enquanto integridade contempla características da natureza humana referentes ao valor intrínseco, bem como, aspectos que são adquiridos ou construídos nas relações entre indivíduos, entre indivíduos e grupos e entre grupos no contexto social, entendidos aqui como sendo aspectos referentes ao status moral. A depender de como ocorram as relações interpessoais e sociais, em termos de simetria ou assimetria, essas poderão influenciar, de maneira direta ou indireta, a preservação, promoção ou violação da identidade humana. (JACOBSON, 2007; JACOBSON, 2009). A dignidade enquanto integridade destaca-se, principalmente, a partir da Segunda Guerra Mundial na Declaração de Direitos Humanos (HABERMAS, 2010).

A fim de ilustrar as diversas concepções de dignidade humana e respectivas raízes ao longo da História, possibilitando uma melhor compreensão acerca do assunto abordado anteriormente, elaborou-se o Quadro 02. Onde, abordam-se as concepções ou sentido de dignidade ao longo da História, desde a Antiguidade, passando pelo Renascimento, Idade Moderna até a Atualidade.

QUADRO 02: Dignidade humana e suas raízes.

\begin{tabular}{|l|l|l|l|}
\hline \multicolumn{2}{|l|}{ Período Histórico/Local } & Concepção ou sentido de Dignidade \\
\hline \multirow{2}{*}{$\begin{array}{l}\text { Antiguidade } \\
\text { (SARLET, 2010) }\end{array}$} & Grécia & $\begin{array}{l}\text { Sociopolítica ou do mérito e } \\
\text { valor intrínseco }\end{array}$ & $\begin{array}{l}\text { Pensamento clássico grego - a dignidade relacionava-se a } \\
\text { posiçes de destaque }\end{array}$ \\
\cline { 3 - 4 } & & $\begin{array}{l}\text { Pensamento estoico grego - homem acima das demais } \\
\text { criaturas, tendo a dignidade como uma qualidade } \\
\text { inerente ao ser humano (valor intrínseco). }\end{array}$ \\
\hline
\end{tabular}




\begin{tabular}{|c|c|c|c|}
\hline & \multirow[b]{2}{*}{ Roma } & \multirow[b]{2}{*}{$\begin{array}{l}\text { sociopolítica ou do mérito e } \\
\text { valor intrínseco }\end{array}$} & $\begin{array}{l}\text { posição social ocupada pelo indivíduo e ao seu grau de } \\
\text { reconhecimento pelos demais membros da sociedade. }\end{array}$ \\
\hline & & & $\begin{array}{l}\text { Filosofia estoica (Cícero): Todo ser humano tem algum } \\
\text { grau de dignidade preservado em sua natureza humana, } \\
\text { independente da hierarquia social ou do status pessoal, } \\
\text { embora também reconhecesse a existência da dignidade } \\
\text { enquanto status social (BARRETO, 2006; SARLET, 2010; } \\
\text { GOSDAL, 2007). }\end{array}$ \\
\hline \multirow{2}{*}{\multicolumn{2}{|c|}{$\begin{array}{l}\text { Idade Média } \\
\text { (GOSDAL, 2007) }\end{array}$}} & \multirow{2}{*}{$\begin{array}{l}\text { Dignidade sociopolítica e de } \\
\text { valor intrínseco (Igreja } \\
\text { Católica) }\end{array}$} & $\begin{array}{l}\text { sociopolítica permaneceu sendo conquistada } \\
\text { socialmente por meio de status: nobres, cavaleiros e } \\
\text { clero. }\end{array}$ \\
\hline & & & $\begin{array}{l}\text { valor intrínseco foi defendida por São Tomás de Aquino, } \\
\text { que usou o termo 'dignitas humana' para simbolizar a } \\
\text { igualdade dos homens perante Deus. }\end{array}$ \\
\hline \multicolumn{3}{|c|}{$\begin{array}{l}\text { Renascimento } \\
\text { Marco: O escrito 'Oratio de hominis dignitate', de Giovanni Pico } \\
\text { Della Mirandola / Dignidade associada à liberdade concedida pelo } \\
\text { criador e respectiva responsabilidade pelas escolhas realizadas } \\
\text { (SARLET, 2010; GOSDAL, 2007). }\end{array}$} & $\begin{array}{l}\text { Permanece o sentido de que dignidade se relaciona ao } \\
\text { cargo ou função social, derivando-se a honra e a } \\
\text { deferência, cujo desrespeito poderia ser sancionado com } \\
\text { medidas civis e penais (BARROSO, 2012). }\end{array}$ \\
\hline \multicolumn{3}{|c|}{ Idade Moderna (XVII e XVIII) } & $\begin{array}{l}\text { Valor intrínseco: A razão possibilita autonomia para } \\
\text { pensar e agir (KANT, 2005) }\end{array}$ \\
\hline \multirow{5}{*}{\multicolumn{2}{|c|}{$\begin{array}{l}\text { Atualidade/(XXI) (TADD et al. } \\
\text { 2010; NORDENFELT, 2003; } \\
\text { NORDENFELT, 2004) }\end{array}$}} & \multirow{2}{*}{ Sociopolítica ou do mérito } & Ocidente: cargo/ posição social \\
\hline & & & Oriente (China): face (KOEHN et al., 2008) \\
\hline & & \multicolumn{2}{|c|}{ Status moral: importância da autonomia moral } \\
\hline & & \multicolumn{2}{|c|}{$\begin{array}{l}\text { Valor intrínseco: Políticas Nacionais e Internacionais/ Declaração dos Direitos Humanos } \\
\text { (MATTSON et al., 2011) / Constituições nacionais (SARLET, 2010). }\end{array}$} \\
\hline & & \multicolumn{2}{|c|}{$\begin{array}{l}\text { Identidade ou Integridade (contempla características da natureza humana referentes ao } \\
\text { valor intrínseco e aspectos construídos nas relações interpessoais, entendidos aqui como } \\
\text { status moral), possibilitando a preservação, promoção ou violação da identidade humana } \\
\text { (JACOBSON, 2009) }\end{array}$} \\
\hline
\end{tabular}

\section{Dignidade nas Organizações e Dignidade das Organizações}

A dignidade nas organizações leva em consideração o ambiente interno à organização e as respectivas relações estabelecidas entre trabalhadores, destacando tanto os aspectos referentes ao trabalhador propriamente dito, como as condições de trabalho. Abrange estudos sobre a dignidade do trabalhador que se refere aos sentimentos e percepções do trabalhador em relação ao seu trabalho (HODSON, ROSCIGNO, 2004) e também sobre a dignidade no trabalho, que corresponde às próprias condições do ambiente de trabalho, como salubridade, higiene (AGASSI, 1986), preocupações com a prevenção da violência (WAY, 2001) e do bullyng (SUNDER, 2013).

Melhor esclarecendo, a revisão da literatura acerca da dignidade humana nas organizações, ao levar em consideração tanto os aspectos relacionados ao trabalhador quanto às condições de trabalho, possibilitou identificar que o mencionado tema é tratado sob os seguintes aspectos: significado do trabalho na vida das pessoas e trabalho decente (PRYOR et al., 1989; GHAl, 2003; HEPPLE, 2001); ética no trabalho (WARREN, 2005); direitos Humanos (HUBBARD, 2006); dignidade no setor Público (ROSOW, 1979); economia (LUTZ, 1995; MCMASTER, 2013); terceira idade (STONE, 2011); gênero, trabalho e dignidade (CROWLEY, 2013; ROSS, 2013); saúde e dignidade Humana (PICHLER, 2005; HAVILAND et al., 2003; HORTON, 2004); aspectos negativos do trabalho, no que se refere aos fatores que afetam a dignidade do trabalhador nas relações com 
os outros trabalhadores e também em situações de downsizing (GREENSPAN, 2002; BARBEE, 2001); baixos salários e baixa qualidade nos serviços dos trabalhadores (BERG et al., 2005).

Além destes, a dignidade humana no trabalho é tratada sob os seguintes temas: reações para trabalhos fisicamente perigosos (JERMIER et al., 1989); violência e stress no trabalho (WAY, 2001); condições de trabalho para os colaboradores, que trabalham meio período ou esporadicamente, principalmente no que diz respeito ao stress do trabalhador e consequências de seus stress para o ambiente de trabalho (ZEYTINOGLU et al. et al., 2004); assédio moral (HELOANI, 2004); propostas para inserção de dignidade no local de trabalho: proteger a dignidade no local de trabalho, mediante o estabelecimento da confidência e da confiança mútua nas relações entre trabalhadores e gestores, principalmente em casos de demissão (BRODIE, 2004); trabalho organizado, como uma forma de estabelecer uma nova dignidade no local de trabalho (AUERBACH, 1988); programas políticos (HYMAN, 1952); delineando a dignidade no local de trabalho (AGASSI, 1986); dignidade e implicações para os líderes (SABBAGHI et al., 2013; dignidade como uma maneira de prevenir os efeitos negativos do bullying, tanto para as pessoas que foram vítimas, quanto para as organizações (SUNDER, 2013) e, dignidade e eficácia nas equipes de gerenciamento, com base nos comportamentos e reações de jovens executivos e gerentes seniors presentes nas discussões sobre questões financeiras e seus impactos na organização (MACHER, 2000); e sucesso organizacional, definido como sendo o elevado esforço do indivíduo no trabalho, à dignidade do trabalhador que, por sua vez, está relacionada às condições de trabalho (HODSON et al., 2004).

No que diz respeito ao estudo de dignidade das organizações, notou-se na literatura investigada, que as pesquisas se baseiam predominantemente na avaliação interna e/ou externa à organização, mediante sua relação com os stakeholders. Os stakeholders correspondem a qualquer indivíduo ou grupo de trabalhadores, clientes, fornecedores e acionistas, que podem interferir, de maneira direta ou indireta, na elaboração e concretização dos objetivos organizacionais (GRIFFIN-HESLIN, 2005; FREEMAN, 1984), num processo contínuo de construção e reconstrução, mediante interações e linguagem (TEIXEIRA, 2008).

Dentre os exemplos de estudos que analisam a relação entre organizações e stakeholders, destacamse: Araujo (2013), ao buscar compreender como são socialmente construídos os significados de dignidade no âmbito da relação entre uma comunidade local e as empresas situadas em sua imediação geográfica; Passos Junior (2014) ao identificar os sentidos da dignidade no relacionamento entre empresa e comunidade na perspectiva dos gestores da empresa. Malini (2014) ao analisar a influência da cultura organizacional nas práticas de dignidade organizacional, estabelecidas entre as empresas e os stakeholders a partir da percepção de empregados. Teixeira et al. (2014) ao avaliarem as práticas de dignidade organizacional, percebidas pelos trabalhadores, considerando-os interligados numa rede de relacionamentos entre organização, clientes e sociedade. Medeiros et al. (2014) ao buscarem compreender os limites da dignidade dos docentes nas práticas de gestão em universidades brasileiras.

Apesar dos estudos sobre dignidade nas organizações e dignidade das organizações preocuparemse; de maneira comum, analisar e compreender a dignidade humana em contextos organizacionais, evidencia- se entre estas duas concepções, algumas divergências de interesse, conforme apontadas a seguir. 
Os estudos sobre dignidade nas organizações interessam-se, principalmente, em compreender questões referentes à dignidade nas relações existentes no ambiente interno da organização, seja no enfoque do trabalhador ou do trabalho. Já os estudos de dignidade das organizações focalizam a relação entre empresas e stakeholders.

Enquanto a avaliação interna à organização é bastante investigada na literatura, sob o enfoque de dignidade do trabalhador e dignidade no trabalho, a avaliação externa à organização passou a ser explorada recentemente no Brasil, tendo como um dos seus principais marcos os estudos de Teixeira (2008), que ampliaram a visão de dignidade nas organizações, restritas até então ao ambiente interno. Para esta autora, dignidade organizacional refere-se à relação entre as pessoas da organização e os stakeholders, em que se diz o que se pensa sem intenção de usar o outro para atingir seus próprios objetivos, estabelecendo acordos com base no entendimento.

Teixeira (2008), levando em consideração os interesses dos stakeholders, diz que gerenciar na perspectiva destes é uma demanda da gestão atual, que amplia a performance da empresa. A autora considera que as organizações são como sistemas abertos, estando permeadas por diversas relações de influência e aliadas às características de não serem auto independentes e nem autossuficientes.

\section{CONCLUSÕES}

O presente artigo teve como objetivo principal compreender as concepções de dignidade humana no contexto organizacional e suas diferentes concepções. Este objetivo foi alcançado com os estudos realizados e procedimentos metodológicos adotados.

A revisão da literatura possibilitou identificar que a concepção de dignidade humana não é única, mas múltipla, ambígua, ampla, vaga, multifacetada, não universal, não linear, complexa, aberta a reformulações, diversificada ao longo do tempo e do espaço. Não se trata de uma concepção ser melhor ou pior do que outra e, sim, de diferentes olhares acerca do mesmo termo.

No âmbito dos estudos em organizações, notou-se que, ao abordar dignidade nas organizações, os estudiosos dedicam-se, principalmente, a investigar como as relações de dignidade são construídas no ambiente interno da organização, mediante as relações estabelecidas entre os diversos trabalhadores que pertencem a níveis hierárquicos (semelhantes e distintos) e as respectivas condições de trabalho, as quais estão sendo submetidos no dia a dia laboral. Já os estudos que se referem a investigar dignidade, no âmbito das organizações, preocupam-se, principalmente, em conhecer e compreender as avaliações que os diversos stakeholders, externos à organização, fazem, numa perspectiva de buscar alternativas para o melhoramento das práticas de dignidade nas organizações. Sendo assim, percebe-se que estes dois eixos de análise não são excludentes, e sim complementares, devendo ser estudados de maneira conjunta, tendo em vista que um influencia o outro.

Espera-se que o presente artigo tenha contribuído para uma melhor compreensão dos estudos sobre dignidade humana no âmbito organizacional, principalmente no que se refere a possibilidade de repensar estilos de gestão, na direção de resgatar a dignidade da pessoa humana no ambiente de trabalho. Logo, é 
importante que se continue investigando a dignidade humana em estudos organizacionais, levando-se em consideração que os dois eixos de análise favorecem, de maneira complementar, uma visão mais acurada da organização como um todo.

Um dos limites do estudo consiste em não ter investigado empiricamente o que os estudiosos da área pensam acerca da complementariedade entre dignidade nas e das organizações, bem como sobre a importância de gerenciar na perspectiva de respeito à dignidade da pessoa humana, o que poderá ser analisado em outro estudo, constituindo-se numa agenda de pesquisa.

\section{REFERÊNCIAS}

AGASSI, J. B.. Dignity in the Workplace Can Work Be Dealienated?. Journal of Business Ethics, v.5, p.271-284, 1986.

ARAUJO, B. F.; VON B.. A Construção dos Significados de Dignidade no âmbito da relação entre Empresas e Comunidade. In: ENCONTRO DA ANPAD, 37. Anais. ANPAD, 2013.

AUERBACH, J.. Organized Labor: Toward A New Dignity in the Workplace. Journal of Career Development, v.15, n.1, 1988.

BARBEE, G. E.. Downsizing with Dignity: Easing the Pain of Employee Layoffs. Business and Society Review, 2001.

BARROSO, L. R.. Aqui, lá e em todo lugar: A dignidade humana no direito contemporâneo e no discurso transnacional. Revista dos Tribunais, v.9, n.19, 2012.

BERG, P., FROST, A.. Dignity at Work for Low Wage, Low Skil Service Workers. In Industrial Relations, v.60, n.4, 2005.

BARRETTO, V. P.. Dicionário de Filosofia do Direito. Rio de Janeiro: Un, 2006.

BRODIE, D.. Protecting Dignity in the Workplace: The Vitality of Mutual Trust and Confidence. Industrial Law Journal, v.33, p.349-354, 2004.

COHEN, D.; LEUNG, A. K. Y.. Violence and Character: A CuPS (Culture X Person X Situation) Perspective. In: SHAVER, P. R.; MIKULINCER, M.. Human Aggression and Violence: Causes, Manifestations, and Consequences. Washington DC: American Psychological Association, 2011. p.187-200

CROWLEY, M.. Gender, the Labor Process and Dignity at Work. Social Forces, v.91, p.1209-1238, 2013.

FERREIRA, A. B. H.. Novo Dicionário da Língua Portuguesa. 2 ed. Rio de Janeiro: 1986.

FREEMAN, E. R.. Strategic management: a stakeholder approach. Boston: Pitman, 1984.

GHAI, D.. Decent Work: Concept and indicators. International Labour Review, v.142, n.2, p.113-145, 2003.

GOSDAL, T.. Dignidade do trabalhador: um conceito construído sob o paradigma do trabalho decente e da honra. 2007.
GREENSPAN, D. S.. Downsizing with Dignity. Wiley InterScience, 2002.

GRIFFIN-HESLIN, V.. An analysis of the concept dignity. Accident and Emergency Nursing, v.13, p.251-257, 2005.

HABERMAS, J.. O discurso filosófico da modernidade. São Paulo: Martins Fontes, 2010.

HAVILAND, L.; HEALTON, C. G.; FEE, E.; BROWN, T. M.; TOOMEY, B. A.; KASTENS, B.. Courage and Dignity. American Journal of Public Health, v.93, n.7, 2003.

HELOANI, R.. Assédio Moral: Um ensaio sobre a expropriação da dignidade no trabalho. 2004.

HEPPLE, B.. Equality and empowerment for decent work. International Labour Review, v.140, n.1, 2001.

HODSON, R., ROSCIGNO, V. J.. Organizational success and worker dignity: complementary or contradictory?. The American Journal of Sociology, v.110, n.3, p.672-708, 2004.

HORTON, R.. Rediscovering human dignity. Public Health, v.364, 2004.

HOUAISS, A.; VILLAR, M. S.. Dicionário Houaiss da Língua Portuguesa. Rio de Janeiro: 2001

HUBBARD, D.. What Kindof Globalization?. Organizing for Workers' Human Rights. v.9, p.315-335, 2006.

HYMAN, D. A.. Does Technology spell trouble with a capital "T"?: Human Dignity and Public Policy. Harvard Journal of Law \& Public Policy, v.27, 1952.

JACOBSON, N.. Dignity and health: a review. v.64, p.292302, 2007.

JACOBSON, N.. A taxonomy of dignity: a grounded theory study. BMC International Health and Human Rights, v.9, n.3, p.1-14, 2009.

JERMIER, J. M.; GAINES, J.; MCINTOSH, N. J.. Reactions to physically dangerous work: a conceptual and empirical analysis. Journal of Organizational Behavior, v.10, p.15-33, 1989.

JUNIOR, J. R. P.. O Sentido da Dignidade no Âmbito das Relações entre Empresa e Comunidade: a perspectiva dos 
gestores da organização. In: ENCONTRO DA ANPAD, 38. Anais. ANPAD, 2014.

KANT, I.. Fundamentação da Metafísica dos Costumes e outros escritos. São Paulo: Martins Claret, 2005

KOEHN, D.; LEUNG, A.. Dignity in Western Versus in Chinese Cultures: Theoretical Overview and Practical Illustrations. Business and Society Review, v.113, n.4, p.477-504, 2008.

KIM, Y. H.; COHEN, D.; AU, W. T.. The jury and abjury of my peers: The self in face and dignity cultures. Journal of Personality and Social Psychology, v.98, n.6, p.904- 916, 2010. DOI: http://doi.org/10.1037/a0017936

KIM, Y. H.; COHEN, D.. Information, Perspective, and Judgments About the Self in Face and Dignity Cultures. Personality and Social Psychological Bulletin, v.36, p.537550, 2010.

LUTZ, M. A.. Centering Social Economics on Human Dignity. Review of Social Economy, v.53, n.2, 1995.

MACHER, K. Productive conversations: for the dignity and effectiveness of management teams. The Journal for Quality \& Participation, 2000.

MALINI, E.. Cultura Organizacional e Práticas de Dignidade Organizacional: Uma análise por meio de Equação Estrutural. In: ENCONTRO DA ANPAD, 38. Anais. ANPAD, 2014.

MATTSON, J. D. E.; CLARK, S.. Human dignity in concept and practice. Policy Sei, v.44, p.303-319, 2011.

MCMASTER, R.. Mainstream Health Economics and Dignity: The Commodity Narrative as a Debilitating Solecism?. American Journal of Economics and Sociology, v.72, n.1, p.1-32, 2013.

MEDEIROS, A. L.; TEIXEIRA, M. L. M.. Limites da Dignidade dos Docentes nas Práticas de Gestão em Universidades Brasileiras. In: ENANPAD. Anais. 2014.

NORDENFELT, L.. Dignity and the Care of the Elderly. Medicine, Health Care and Philosophy, v.6, p.103-110, 2003.

NORDENFELT, L.. The Varieties of Dignity. Health Care Analysis, v.12, p.69-81, 2004.

OECD, W.. Dignity and people. OECD, 2013.

PICHLER, F.. Debate Science and Human Dignity Ethical questions on the funding of human embryonic stem cell research in the Sixth Framework Programme of the European Commission for research, technological development and demonstration. Innovation: The European
Journal of Social Science Research, v.18, n.2, p.261-272, 2005.

PRYOR, R. G. L.; DAVIES, R.. A Comparison of Conceptualizations of Work Centrality. Journal of Organizational Behavior, v.10, p.289-283, 1989.

ROSOW, J.. Human Dignity in the Public-Sector Workplace. Public Personnel Management, 1979.

ROSS, R. F. S.. Bread and Roses: Women Workers and the Struggle for Dignity and Respect. The journal of labor \& society, v.16, p.59-68, 2013.

SABBAGHI, O.; GERALD, F.; CAVANAGH, S. J.; TIM HIPSKIND, S.. Service-Learning and Leadership: Evidence from Teaching Financial Literacy. Journal Bus Ethics, v.118, p.127-37, 2013.

SARLET, I.. Dignidade da Pessoa Humana e Direitos Fundamentais na Constituição Federal. 8 ed. Porto Alegre: Livraria do Advogado, 2010.

STONE, S.. Treating older people with dignity and respect. Nursing Management, v.18, n.4, 2011.

SUNDER, D. L.. Putting Dignity at Workplace on the Corporate Governance Agenda. India Journal of Corporate Governance, v.6, n.1, p.32-49, 2013.

TADD, W.; VANLAERE, L.; GASTMANS, C.. Clarifying the Concept of Human Dignity in the Care of the Elderly: A dialogue between empirical and Philosophical Approaches. Ethical Perspectives, v.17, n.1, p.253-281, 2010.

TEIXEIRA, M. L.. Dignidade Organizacional: valores e relações com stakeholders. In: Valores Humanos e Gestão: novas perspectivas. Sao Paulo: SENAC, 2008a.

TEIXEIRA, M. L. M., DOMENICO, S. M. R., DIAS, S. M. R. C., MENDES, L. H. L.. Práticas de Dignidade Organizacional Percebidas por Trabalhadores na Relação entre Organizações e stakeholders. In: Encontro da ANPAD, 38. Anais. ANPAD, 2014.

WARREN, R.. Ethics and Service Work. The Service Industries Journal, v.25, n.8, p.999-1014, 2005.

WAY, P.. Shovel and Shamrock: Irish Workers and Labor Violence in the Digging of the Chesapeake and Ohio CanalLabor History. 2001.

WEEK, O. R. G. O.. Dignity and people. 2013.

ZEYTINOGLU, I. U., LILLEVIK, W., SEATON, M. B., MORUZ, J.. Part-Time and Casual Work in Retail Trade- Stress and other Factors Affecting the Workplace. Relations Industrielles, v.59, n.3, p.516-544, 2004.

A CBPC - Companhia Brasileira de Produção Científica (CNPJ: 11.221.422/0001-03) detém os direitos materiais desta publicação. Os direitos referem-se à publicação do trabalho em qualquer parte do mundo, incluindo os direitos às renovações, expansões e disseminações da contribuição, bem como outros direitos subsidiários. Todos os trabalhos publicados eletronicamente poderão posteriormente ser publicados em coletâneas impressas sob coordenação da Sustenere Publishing, da Companhia Brasileira de Produção Científica e seus parceiros autorizados. Os (as) autores (as) preservam os direitos autorais, mas não têm permissão para a publicação da contribuição em outro meio, impresso ou digital, em português ou em tradução. 